\title{
Control Over the Optical and Morphological Properties of UV-Deposited Structures of Porphyrins
}

Giovanna De Luca, Gianmichele Pollicino, Andrea Romeo, Salvatore Patanè and Luigi Monsù Scolaro*

Supporting Information 

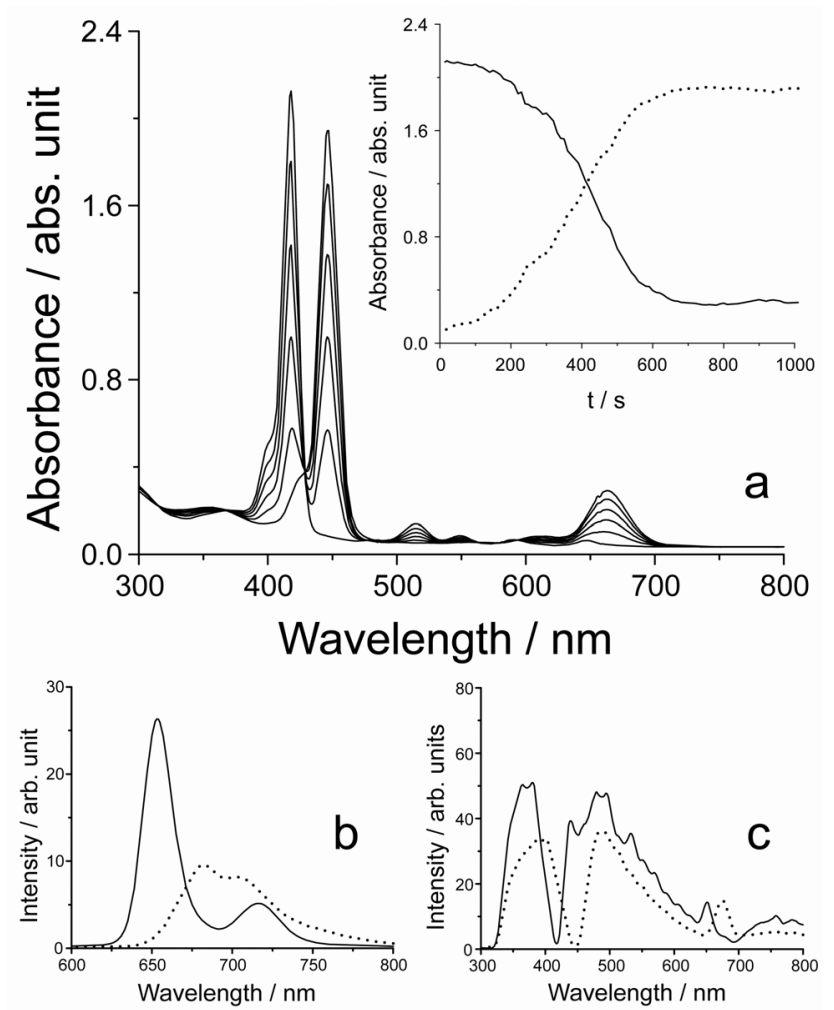

Figure SI1. a) Changes in the absorption spectra occurring upon irradiation of a TPP solution in $\mathrm{CH}_{2} \mathrm{Cl}_{2}$ with a spectrophotometer lamp: [TPP] $5 \mu \mathrm{M}$, i.t.= $0.5 \mathrm{~s}$; d.t.= $5 \mathrm{~s}$; t.t.= $1000 \mathrm{~s}$; under stirring. Inset: changes observed at $418 \mathrm{~nm}$ (solid line) and $446 \mathrm{~nm}$ (dotted line). b and c) Fluorescence and RLS spectra, respectively, of the solution, before (solid line) and after (dotted line) irradiation. 


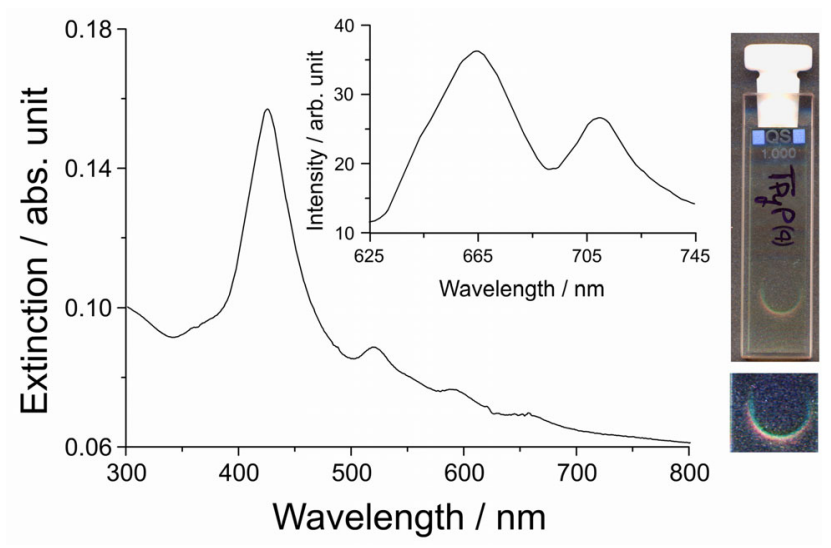

Figure SI2. Extinction spectrum of the $\mathrm{TpyP}(4)$ sample deposited on the wall of the cell by pulsed irradiating the porphyrin solution with a spectrophotometer lamp. $[\mathrm{TpyP}(4)] \sim 6 \mu \mathrm{M}$, i.t. $=0.3 \mathrm{~s}$, d.t. $=10$ $\mathrm{s}$, t.t. $=3600 \mathrm{~s}$. In the inset: corresponding fluorescence spectrum $\left(\lambda_{\mathrm{exc}}=442 \mathrm{~nm}\right)$. On the right: pictures of the deposited sample.

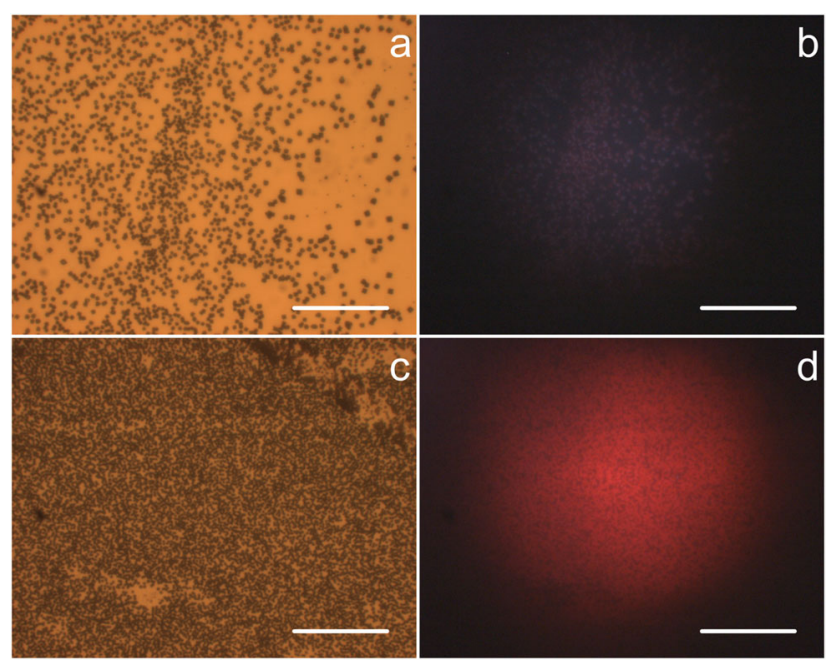

Figure SI3. Optical images of the deposits obtained by irradiating $\mathrm{CH}_{2} \mathrm{Cl}_{2}$ solutions of TpyP(2) (a and b) and TpyP(3) (c and d). UV light source: spectrophotometer lamp, i.t.=0.3 s, d.t.=10 s, t.t.= $3600 \mathrm{~s}$; porphyrins concentration $\sim 6 \mu \mathrm{M}$. a, c) transmission; b, d) fluorescence. Bar: $50 \mu \mathrm{m}$. 